\author{
Mariusz Maziarz \\ Wrocław University of Economics, Poland \\ e-mail: mariusz.maziarz@ue.wroc.pl
}

\title{
Ethics, Uncertainty, and Macroeconomics ${ }^{1}$
}

\begin{abstract}
In this article, I focus on the difference in moral judgment of macroeconomic interventions between the deterministic world of a thought experiment and the uncertain reality. The macroeconomic theory coined by Keynes is, in its most popular reading, deterministic and justifies interventionism. However, incorporating uncertainty into the analysis leads to the contrary result. Namely, if economic output is a random process, such as Gaussian white noise or a stochastic Markov chain, then intervening can bring either economic recovery or inflationary pressure and a next bubble. In the trolley-problem philosophy, the one who pulls the lever instead of the trolley itself is believed to be guilty of the death of an innocent passer-by standing on the side track. Similarly, if the Federal Reserve decided to intervene and failed (causing a bubble on the house market, instantiating), their monetary policy can be said to be a cause of the financial crisis. Therefore, governments should refrain from interventions.
\end{abstract}

Keywords: uncertainty, monetary policy, fiscal policy, recession, macroeconomics

JEL Classification: B41, E32, E37, E52, Z13

\footnotetext{
${ }^{1}$ The author would like to gratefully acknowledge the support received from the National Science Centre, Poland under grant No. 2015/19/N/HS1/01066 and helpful discussions on the current state of macroeconomics with Dr Bartosz Scheuer. The comments voiced by the anonymous "Annales..." reviewers greatly contributed to the argument put forth in this article.
} 


\author{
We are all faced throughout our lives with agonizing \\ decisions. Moral choices. Some are on a grand scale. \\ Most of these choices are on lesser points. But! We define \\ ourselves by the choices we have made. \\ Professor Levy in Woody Allen's \\ Crimes and Misdemeanours
}

\title{
1. Introduction
}

The trolley problem had to be solved in real life. In Oakland, Daphne Jones approached it from the utilitarian viewpoint. She pulled a trolley switch in order to save 5 lives and was found guilty of murdering a passer-by who happened to be standing on the other track. ${ }^{2}$ The sentence was motivated by Ms. Jones' acknowledgment of the fact that her action would save five people but kill Chester Farley. In contrast to the imaginary world of thought experiments, assuming that no one is tied to the track, there is no certainty in decision-making. In real life, Ms. Jones could only act according to predictions on whether the people standing in front of a speeding trolley are able to run away or not.

In the literature, there is a very limited number of analyses whose authors incorporate uncertainty into the trolley-problem. To the best of my knowledge, Han et. al. ${ }^{3}$ are the first philosophers who indicated uncertainty as a possible reason why people questioned by moral psychologists are likely to pull the lever but not to push down an overweight stranger on the track. Namely, it is the unavoidable death of the fat man and the possibility that the person standing on the side-track will slip away that make the difference. However, most philosophers living in the deterministic world of thought experiments argued that the moral judgments of these two situations differ because of incorporating the doctrine of double effect introduced by Thomas Aquinas. ${ }^{4}$

Similarly, the vast majority of macroeconomists and monetary-policy specialists believe in the necessity of conducting monetary and fiscal interventions. In this essay, I argue in favor of the contrary point of view. Namely, I show that the popularly held belief is only justified as long as the economy is a deterministic process. However, incorporating uncertainty into this analysis shows that active monetary and fiscal policy can expand the cyclical changes of the economic output instead of reducing it. The essay consists of four sections. First, I discuss Keynesian macroeconomic theory in its deterministic form and

\footnotetext{
${ }^{2}$ Th. Cathcart, The Trolley Problem, or Would You Throw the Fat Guy Off the Bridge? A Philosophical Conundrum, Workman Publishing, New York 2013, p. 11. The story described in the popular introduction to analytical ethics is imaginary, however, giving names makes the trolley-problem considerations more thrilling. ${ }^{3}$ J. Han, A. Saptawijaya, L. Pereira, Moral reasoning under uncertainty, "International Conference on Logic for Programming Artificial Intelligence and Reasoning”, Springer, Berlin 2012.

${ }^{4}$ A. Lanteri, Ch. Chelini, S. Rizzello, An Experimental Investigation of Emotions and Reasoning in the Trolley Problem, "Journal of Business Ethics" 2008, Vol. 83, pp. 789-804.
} 
conclude that this kind of reasoning justifies interventionism. Second, in order to bridge the gap between the two worlds of theory and reality, I analyze the business cycle as a random process in terms of the real business-cycle theory (RBC theory). Third, I generalize the trolley problem by incorporating uncertainty and, by analogy, analyze if policymakers should intervene. Finally, I conclude by indicating that (1) it is better to observe a recession than to cause one, (2) economic interventions are doomed if the economic world is inherently indeterministic, and (3) governments should refrain from intervening in order not to be accused of causing recessions.

\section{Macroeconomics from the Keynesian perspective}

At the onset of the last financial crisis of 2007-2008, Keynesian thought came back to mainstream economics and the previously popular belief in self-regulating markets faded away. Several of the most influential economists repeated Keynes' theory when they were formulating a cure for the crisis (cf., Nobel Laureate voices: Robert Shiller's last book The subprime solution 5 or Paul Krugman's The New York Times article $^{6}$ ) and highlighted the necessity of government interventions. In a similar vein, several central banks (American, British, and German, among others) pursued multi-billion bailouts in order to stimulate the economy. In spite of a few opponents of the stimuli packages, the interventionist viewpoint became mainstream. Among others, Robert Lucas questioned the theoretical assumptions underlying the current fiscal policy ${ }^{7}$ and Robert Barro with Gary Becker indicated that there is no empirical evidence supporting fiscal expansion ${ }^{8}$ (however, the opposite is believed to be true by most economists).

In general, ${ }^{9}$ Keynesian economists believe that depressions are caused by an insufficient level of demand. The macroeconomic situation can be analyzed in terms of the Hicks-Hansen model given by the following two equations aimed at finding a general equilibrium between investment and saving (IS), and between liquidity preference and money supply (LM): ${ }^{10}$

\footnotetext{
${ }^{5}$ R. Shiller, The Subprime Solution: How Today's Global Financial Crisis Happened, and what to Do about it, Princeton University Press, Princeton 2012.

${ }^{6}$ P. Krugman, Fighting Off Depression, "The New York Times", 5 th January 2009. http://www.nytimes. com/2009/01/05/opinion/05krugman.html?_r=0 (retrieved: $26^{\text {th }}$ September 2009).

${ }^{7}$ R. Lucas, The other-worldly philosophers, “The Economist", 16 ${ }^{\text {th }}$ July 2009, http://www.economist.com/ node/14030288 (retrieved: $26^{\text {th }}$ September 2009).

${ }^{8}$ R.J. Barro, Keynesian Economics vs. Regular Economics, “The Wall Street Journal”, $23^{\text {rd }}$ August 2011.

${ }^{9}$ Here, I briefly discuss neo-Keynesian economics in the form established by John Hicks, Franco Modigliani and Paul Samuelson. I certainly do not pretend to review the Keynesian school of macroeconomics or cover the whole theory in detail.

${ }^{10}$ L. Klein, IS-LM Model: Its Role in Macroeconomics [in:] IS-LM and Modern Macroeconomics, eds. W. Young, B. Zilberfarb, Springer, Tel Aviv 2012, p. 152.
} 


$$
\begin{gathered}
I(r, Y)=S(r, Y) \\
M=L(r, Y) \\
\text { where: } \\
r-\text { interest rate; } \\
Y-\text { aggregate income; }
\end{gathered}
$$

According to the IS-LM model, demand and employment depend on the following three exogenous variables: government budget, money in circulation, and business expectations. Of the three determinants, the latter two were endogenically lowered when the financial crisis broke. First, financial institutions lost a fraction of their assets due to the bubble on the housing market in the United States and writing off the bad debts. Additionally, at the end of 2008, no one knew which institutions suffered from owing worthless collateralized debt obligations (CDOs) and therefore, because of risk aversion, the interbank loan market evaporated. Second, multi-billion losses reported by several international banks and other financial institutions caused business moods to plunge. This mechanism reduced the aggregated demand which, under the Keynesian condition of sticky prices, lowered the output.

Since policymakers can directly control only the third factor, i.e. government spending, bailouts were implemented in order to bridge the recessionary gap between the potential product and the actual one. ${ }^{11}$ However, the other two factors shaping demand (i.e. money in circulation and business expectations) can be controlled in an indirect way, by means of setting the interest rate. In this approach, reducing interest rates raises the opportunity cost of holding cash instead of other assets (e.g. securities), which usually makes the aggregated demand rise. These are the two methods of policymaking suggested by Keynesian macroeconomics. ${ }^{12}$

\section{Incorporating uncertainty}

Simplifying, ${ }^{13}$ it is justified to highlight that ethical dilemma does not arise if the Keynesian theory is interpreted in a determinist way and we can justifiably believe that the IS-LM model rightly describes the real economy. However, in macroeconomics, there is a nev-

\footnotetext{
${ }^{11}$ The details are delivered, for instance, by Klein (op. cit., pp. 151-161).

${ }^{12}$ Other schools of thought highlight other alternatives, such as changing the institutional setting aimed at making markets more efficient or supporting long-term growth by diminishing the influence of government on economy.

${ }^{13}$ Usually, macroeconomic interventions influence not only how much is produced but also cause wealth redistribution. Therefore, even if one knew with certainty that an intervention would result in macroeconomic recovery, it might be ethically wrong to fund a bailout because interventionism makes innocent people pay for the choices which led to the economic crisis committed by others.
} 
er-ending dispute between right- and left-wing economists. Or, in other words, between interventionists and liberals. Today, there are several macroeconomic theories which are contradictory in several aspects. Macroeconomic interventions are based on theories which, in contrast to the situation of different sciences, are not widely supported or believed to be corroborated. Therefore, ethical judgment on macroeconomic interventions should be grounded in an analysis including uncertainty.

The definitions of uncertainty used in various fields differ to a high degree. Below, I draw from the tradition proposed by economists. Economics has a long history of dealing with the unknown, but uncertainty is still neglected. In relation to this field, there are two degrees of a lack of knowledge: risk and uncertainty. The former term is used to describe situations where alternative scenarios can be described in terms of probability and are perfectly suited to analyze gambling, life insurance issues (thanks to the law of great numbers), and option pricing under the condition of the Gaussian return distribution. By contrast, the latter term is used to describe situations where either probability of alternative scenarios is unknown, or there is no knowledge of possible outcomes. In other words, uncertainty cannot be measured. This differentiation was started in economics by Frank Knight in the early twentieth century:

Uncertainty must be taken in a sense radically distinct from the familiar notion of risk, from which it has never been properly separated... The essential fact is that 'risk' means in some cases a quantity susceptible of measurement, while at other times it is something distinctly not of this character; and there are far-reaching and crucial differences in the bearings of the phenomena depending on which of the two is really present and operating... It will appear that a measurable uncertainty, or 'risk' proper, as we shall use the term, is so far different from an unmeasurable one that it is not in effect an uncertainty at all. ${ }^{14}$

The ethical dilemma of the question whether it is right for a policy-maker to intervene during a recession is also trivial when risk (instead of uncertainty) is incorporated into the analysis, which can be illustrated with the case of considering a bailout during the last financial crisis. Let me consider the following thought experiment (see Graph 1) based on the two-period model: time $t$, when the decision if an intervention should be conducted is made, and $t+1$, the whole future, consisting of all results of the choice. There are three scenarios. First, the policy-maker does not decide to provide public support for financial institutions which own bad debt, some of them fail and, according to the estimates delivered by analysts, economic output is reduced because of a mild recession caused by a few bankrupted banks and raised risk aversion. Second, the policy maker decides to bail out banks, which lowers risk aversion and, by means of raised money in circulation, creates another bubble. ${ }^{15}$ Third, which is more likely, the stimuli package is successful and the economy recovers.

\footnotetext{
${ }^{14}$ F. Knight, op. cit., p. 19.

${ }^{15}$ In fact, it happened a few years ago, when the Federal Reserve decided to stimulate the American economy after the dot-com bubble collapsed in 2001. The interest rates close to the zero bound and fiscal stimulus started the house-market bubble, which resulted in the great recession of the late 2000 s and early 2010 s.
} 
Graph 1. Macroeconomic interventions under risk. An exemplary case study

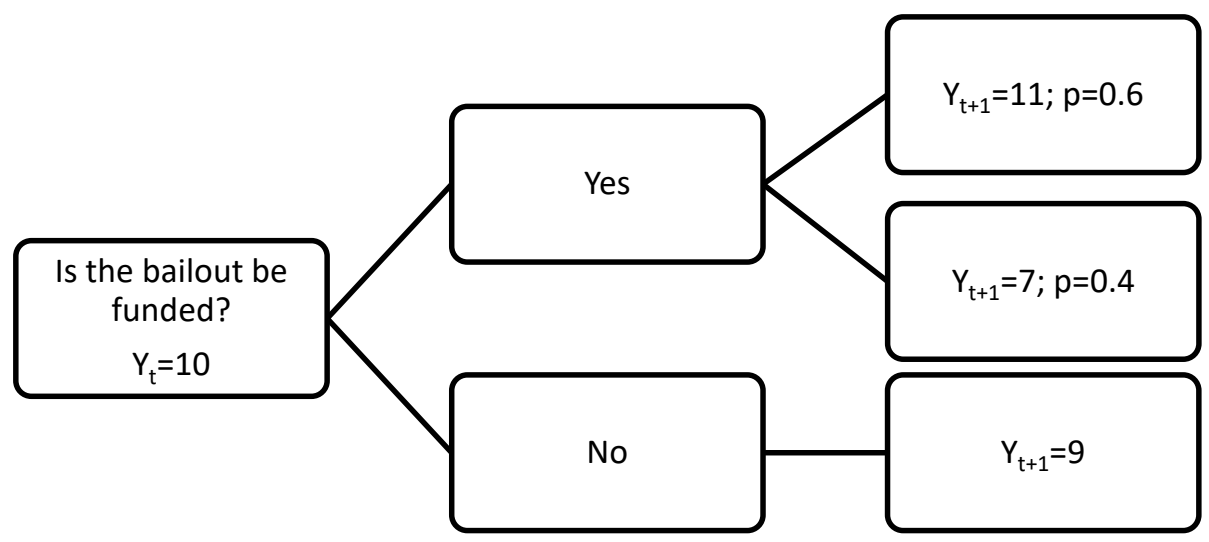

Since risk is understood in economics as a situation of limited knowledge where various scenarios or possibilities can be attributed to its quantifiable likelihood, policy-makers should calculate the expected value of each decision and choose the best, most useful (in terms of the value of output) possibility, i.e. fund the bailout. Here, for simplicity, I assume that the policy-makers ground their decision in utilitarian ethics (which is justified by the long tradition of incorporating this approach into economics) ${ }^{16}$ and do not consider risk aversion. That is, I do not calculate nor consider the variance of the possible outcomes but only the average outcome. Additionally, I do not pretend to make the thought experiment realistic by incorporating the political theory of the business cycle. In other words, policy-makers might be driven by maximizing economic output before the next election.

In contrast to the above thought experiment, there is no certainty in economic policymaking, and describing it in terms of risk instead of uncertainty relies on so many assumptions that, as Uskali Mäki ${ }^{17}$ put it in his most recent critique of the current state of economics, such models irrelevantly resemble reality. There are three kinds unknown in the studied dilemma: (1) whether the IS-LM model relevantly frames the modeled phenomenon, (2) what results the considered intervention will bring, and (3) whether the recession is caused by reduced demand. All these doubts are interconnected and still provoke lively discussions among economists. Simplifying, the IS-LM model can be believed to possess essesimilitude when recessions are caused by reduced demands. In this case, only the second question remains open. In other words, it is unknown what results will bring an intervention. The stimuli package can be too small to make the economy recover or too huge and raise the inflationary pressure. Aikman et al. ${ }^{18}$ compared economies

${ }^{16}$ G. Mankiw, Principles of Microeconomics, Cengage Learning, New York 2008, p. 442; R. Posner, The Economics of Justice, Harvard University Press, Harvard 1983, p. 48. Posner explicitly states that economics is equated with utilitarianism in some circles.

${ }^{17}$ U. Mäki, Modelling failure [in:] H. Leitgeb, I. Niiniluoto et al., Logic, Methodology and Philosophy of Science-Proceedings of the $15^{\text {th }}$ International Congress, College Publications, Helsinki 2016, p. 6.

${ }^{18}$ D. Aikman, Ph. Barrett, S. Kapadia et al., Uncertainty in macroeconomic policy-making: art or science?, "Philosophical Transactions of the Royal Society" 2011, Vol. 369, pp. 4798-4817. 
to a complex system and argued that they are, at best, deterministic in a chaotic way and indicated dependence on the 'state of beliefs of the systems' participants"19 as a source of inherent randomness.

Additionally, recessions can also be caused by real, supply-side shocks. According to the real-business-cycle theory, ${ }^{20}$ recessions are observed when exogenous shocks happen. For instance, if an oil tanker sinks then (1) oil prices make production of goods more expensive, (2) customer prices rise and (3) a new general equilibrium is set at higher prices and a lower output. Assuming that this point of view is correct and, like the viewpoint of the efficient-market hypothesis theorists ${ }^{21}$ that both negative and positive shocks happen randomly, then theeconomic product (without considering the changes in technology which would create a positive drift) can be modeled by the following equation:

$$
\begin{gathered}
Y_{t+1}=Y_{t}+\varepsilon \\
\text { where: } \\
Y_{t+1} \text { - output in the } \mathrm{t}+1 \text { year; } \\
Y_{t} \text { - output in the t year; } \\
\varepsilon \text { - influence of a random shock. }
\end{gathered}
$$

In this case, a future economic product depends only on output from the previous year and random exogenous shocks. In other words, interventions do not influence the real economy, only price levels. Which of these two theoretical approaches to macroeconomics is empirically adequate? The never-ending discussions among economists do not seem to lead to a constructive conclusion. Most likely, various theories adequately describe different kinds of macroeconomic environment. For instance, Keynes' approach should be employed to deal with recessions caused by insufficient demand and the real business-cycle theory to understand negative, supply-side shocks. However, I should highlight that what both Keynesian and new neoclassical economists believe in is that macroeconomic interventions aimed at stimulating the economy are only effective (i.e. result in any change in output) if the economic agents (customers and producers, namely) are not aware of the unavoidable tax increases in the future. Therefore, even if a considered recession is caused by demand-side shock, intervention measures might be inefficient. This understanding can be exemplified by the case of American economy suffering from stagflation in the 70 s and early 80 s. $^{22}$

\footnotetext{
${ }^{19}$ Ibidem, p. 4798.

${ }^{20}$ Cf. S. Chugh, Modern Macroeconomics, MIT Press, Cambridge, Massachusetts 2015, p. 203 et seq.

${ }^{21}$ B. Malkiel, E. Fama, Efficient Capital Markets: A Review of Theory and Empirical Work, "The Journal of Finance" 1970, Vol. 25(2), pp. 383-417.

${ }^{22}$ J.O.N. Perkins, The Reform of Macroeconomic Policy. From stagflation to Low or Zero Inflation, Palgrave MacMillan, Melbourne 2016, p. 16.
} 
Graph 2. Sources of uncertainty in economic policy-making

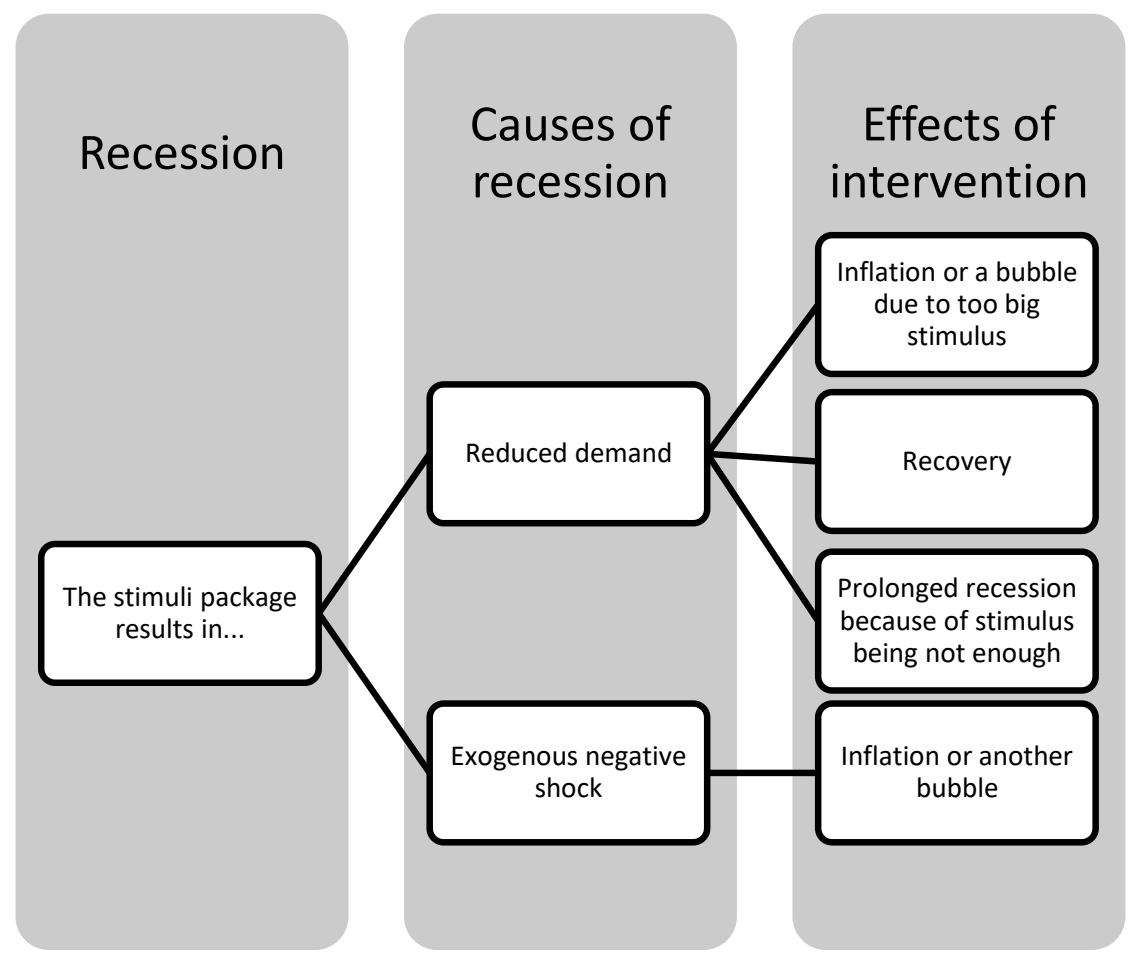

Summing up the above considerations, a policy-maker faces two kinds of uncertainty. First, they have to determine what caused a recession. Second, it is uncertain how the economy will react to the intervention. ${ }^{23}$ If the recession is caused by a negative supply-side shock, as real business-cycle theory states, then any intervention (i.e. changes in either monetary or fiscal policy) will result in an inappropriately huge money supply and either inflation or a speculation bubble. On the other hand, if the recession is caused by a negative demand-side shock, intervention might be fruitful, but the exact results depend on the amount of money spent by the government and they might also result in starting an inflationary process, (see Graph 2).

\section{The ethical dilemma}

Above, I sketched the theoretical framework of macroeconomic policymaking, which, considering the current state of economics and the inherent indeterminism of the economy itself, is a decision-making process under uncertainty. Here, I focus on answering the

${ }^{23}$ J.E. Stiglitz, Rethinking Macroeconomics: What Failed, and how to Repair It?, "Journal of the European Economic Association" 2011, Vol. 9(4), pp. 591-645. Stiglitz shows how macro- and macroeconomic policy failed several times along its history. 
question if economic policymakers should intervene even though the results of such interventions are uncertain, i.e., by the definition coined by Frank Knight, the results cannot be measured even in a probabilistic way.

The policy-making dilemma can be compared to the difference between killing and letting die, raised by Judith Thomson. ${ }^{24}$ She considered several thought experiments with the aim of indicating why people judge various alternatives of the trolley problem in different ways. For instance, most people would pull the lever in order to save 5 lives and kill one. However, the same people would condemn a surgeon who transplanted the organs of a healthy man (killing him) to five terminally ill patients. The difference, as Thomson argued, is between letting five die and killing one:

\section{It is plain that if the bystander throws the switch, he causes the trolley to hit the one, and thus he kills the one. It is equally plain that if the bystander does not throw the switch, he does not cause the trolley to hit the five, he does not kill the five, he merely fails to save them - he lets them die. ${ }^{25}$}

When the trolley problem is discussed with non-philosophers (economics students, for instance), instead of focusing on the ethical dilemma, i.e. choosing if they should pull the lever or not, people argue that there are other options such as shouting at those standing on the track etc. However, even if the tracks were located behind a soundproof glass, in real life, where people are rarely tied to tracks, there is a chance that those miserable workers standing in front of the speeding trolley would get away. Therefore, moral judgments of pulling the lever depend on the likelihood that the people on the tracks will step away. For instance, if the five people on the main track were young, sporty people who could easily run away and the one on the side track was a disabled person, then pulling the lever would indeed equal committing murder.

This intuition might be the reason why most people would not pull the fat man off the bridge to stop the trolley, but they would switch the lever. In the former case, the overweight passer-by would certainly die. In the latter case, other things being equal, there is an inherent uncertainty regarding whether the people on the track would die or step away. Assuming that each worker is equally likely to step off the track, it is more probable that the accident would end happily (i.e. without any blood being shed) if the trolley is directed to the side track. However, the difference in action between the trolley problem with the lever and pushing the fat man off the bridge is usually explained by the doctrine of double effect introduced by Thomas Aquinas, ${ }^{26}$ or neurobiological research which indicates that people think analytically in the latter case and emotionally in the former. ${ }^{27}$ Coming back to the subject of deciding if macroeconomic interventionism is ethically justified under uncertainty, I will consider the following thought experiment:

\footnotetext{
${ }^{24}$ J. Thomson, The Trolley Problem, “The Yale Law Journal” 1985, Vol. 94(6), pp. 1395-1415.

${ }^{25}$ Ibidem, p. 1398.

${ }^{26}$ A. Lanteri, Ch. Chelini, S. Rizzello, op. cit.,

${ }^{27}$ J. Greene et al., Pushing moral buttons: The interaction between personal force and intention in moral judgment, “Cognition” 2009, Vol. 111(3), pp. 364-371.
} 
There is a runaway trolley speeding down the track. There are two tracks ahead (A, the main track and $B$, the side track) behind a brick wall. You are standing next to a lever and know that there are people on both tracks. If you pull the lever, the trolley will switch to a different track. Would you pull the lever?

There are three possibilities to be considered:

$$
\begin{aligned}
& \text { (1) } N_{A}>N_{B} \\
& \text { (2) } N_{A}<N_{B} \\
& \text { (3) } N_{A}=N_{B}
\end{aligned}
$$

$N_{A^{-}}$number of people on the main track A;

$N_{B}$ - number of people on the side track B.

$$
A, B \geq 0 \text {. }
$$

According to the above-discussed definition of uncertainty, there is no knowledge on the number of people on the tracks. Therefore, pulling the lever can result in:

(1) Killing a lower number of people than those saved.

(2) Killing a greater number of people than those saved.

(3) Killing the same number of people than those saved.

Since, as Thomson argued, and Philippa Foot ${ }^{28}$ before her, killing one person is certainly worse than letting one person die, if the passer-by standing near the lever knew that $\mathrm{s} /$ he faced the second or third dilemma, s/he should not intervene. Therefore, intervention, i.e. in this case pulling the lever, is morally justified only in the first case. However, there is no knowledge which of the three scenarios is the case. In other words, the question raised by this version of the trolley-problem is as follows: is it ethically right to save an unknown number of people by killing an unknown number of people? Taking the thought experiment to the extreme, the main track might be empty. Then, as Thomson put it:

Suppose there wasn't anybody on the straight track, and the bystander turned the trolley onto the right-hand track thereby killing the one, by not saving anybody, since nobody was at risk, and thus nobody needed saving. ${ }^{29}$

John Keynes, before he became interest in macroeconomics, earned his Ph.D. in mathematics thanks to his acclaimed dissertation on probability, where he wrote that 'The Principle of Indifference can be claimed to support the most usual hypothesis, namely, that all possible numerical ratios of black and white are equally probable.' ${ }^{30}$ Assuming that $\mathrm{N}=100$ people who are randomly assigned to both tracks, then there are following assignments: $0 / 100$; $1 / 99 ; 2 / 98 ; \ldots ; 98 / 2 ; 99 / 1 ; 100 / 0$. Therefore. The probability that the number of people

\footnotetext{
${ }^{28} \mathrm{Ph}$. Foot, The Problem of Abortion and the Doctrine of the Double Effect, "Oxford Review" 1967, No. 5.

${ }^{29}$ J. Thomson, op. cit., p. 1404.

${ }^{30}$ J. Keynes, A Treatise on Probability, Dover Publications, Mineola 2013, p. 50.
} 
on track $\mathrm{A}$ is higher than on track B is equal to the opposite situation. In this case, if killing is worse than letting die, then intervening is not ethically right and the passer-by should refrain from pulling the lever.

Does economic policymaking differ from the above-described trolley dilemma? First, macroeconomic policy is connected to money and not human lives (not directly, at least). Second, like the differentiation of moral obligations between a passer-by standing near the lever and the driver of the trolley, some people (mainly macroeconomists) would argue that it is the obligation of the economic policymakers to intervene, and suspending action is equally unethical as a mistaken intervention. In other words, like the driver of the trolley, policymakers are in charge of pulling the lever. At present, they are indeed, but a brief look at the history of anti-cyclical economic policy shows that it resulted from macroeconomics, which started in the 1930s when Keynes formulated his theory. Therefore, the ethical situation of a policy maker should be compared to the situation of the person choosing if $\mathrm{s} /$ he should pull the lever instead of the driver. Third, the question regarding whether economic policy really is made under uncertainty sensu stricto should be answered. In macroeconomics, there are several contradictory theories or competing schools of thought which, as I exemplified with Keynesian macroeconomics and the real-business cycle theory, often support the undertaking of contradictory actions. Moreover, historical attempts at stabilizing the business cycle failed several times in many ways and, sometimes, caused more severe economic difficulties than the ones which were the reason for interventions. ${ }^{31}$ Therefore, economic policy-makers should refrain from intervening, because if they do not and fail, then their actions can be indicated as a cause of a future economic recession.

\section{Concluding remarks}

On the one hand, macroeconomic interventions are justified and desired as long as Keynesian macroeconomics adequately describes the real world. On the other hand, alternative theories (e.g. neoclassical economics or the real business-cycle theory) argue that the active macroeconomic policy either is pointless or even leads to negative results such as a rise in inflationary pressure. Therefore, the answer to the question if policy-makers should intervene depends on viewpoints on the verisimilitude of macroeconomic theories. Today, there is no consensus among economists, who support various and often contradictory stances. ${ }^{32}$

\footnotetext{
${ }^{31}$ Two of the most sound examples are the recession transformed into the stagflation of the 70s, because of inappropriate macroeconomic policy and the dot com bubble recessionary measures, which co-caused the great recession of the early 2010s. R. Barsky, L. Kilian, Do We Really Know that Oil Caused the Great Stagflation? A Monetary Alternative, "NBER Macroeconomics Annual" 2001, No. 16, pp. 139-198; V. Acharya et al., The Financial Crisis of 2007-2009: Causes and Remedies, "Financial Markets, Institutions and Instruments" 2009, Vol. 18(2), pp. 89-137.

${ }^{32}$ For an examplary discussion of the contradictions present in the empirical macroeconomics see: M. Maziarz, The Reinhart-Rogoff controversy as an instance of the 'emerging contrary result' phenomenon, "Journal of Economic Methodology" 2017, Vol. 24(3), pp. 213-225.
} 
Above, I have considered two alternative degrees of knowledge on economy possessed by policy-makers. First, the decision-making under risk implies calculating the expected utility of each decision and choosing the best option. Second, I incorporated uncertainty into the analysis. According to the definition widespread among economists, uncertainty describes the state of knowledge where either the possible outcomes or their probabilities are unknown. In this case, deciding if a macroeconomic intervention should be conducted can be compared to the analysis of the trolley problem, where the numbers of people standing on each track are unknown. Assuming that killing is worse than letting die and, accepting the Keynesian Principle of Indifference, ${ }^{33}$ the probability that the number of people on one track exceeds the number standing on the other equals the opposite situation, refraining from pulling the lever is the ethical action from the utilitarian point of view. It is better to observe a recession than to cause one. If a policy-maker possesses limited knowledge on the reason of the current recession and future economic growth, it is better not to intervene, since their action can cause either recovery or create another bubble (and, hence, the intervention could be indicated as the reason for the next economic depression, likely more severe than the current one).

These two situations - risk and uncertainty - constitute two extremes on the scale of knowledge of the macroeconomic situation. Macroeconomic policymakers decide on interventions under circumstances that fall between these two extremes. Therefore, the conclusion from the thought experiment applies to real life as long as the macroeconomic theory is inconsistent, which, I believe, is the case today. The history of active macroeconomic policy, which started in the 1930s, and its numerous failures teach us that economy is such a complex system that it is still not understood well enough to enable each intervention to be fruitful. Employing my reasoning to active policymaking and minimizing thenumber of interventions will reduce the number of failed interventions. This approach may not save the workers standing on the main track, i.e. it may not reduce the variability of economic output, but economic policy-makers will at least no longer be held responsible for the repeating recessions.

\section{References}

Acharya V. et al., The Financial Crisis of 2007-2009: Causes and Remedies, "Financial Markets, Institutions and Instruments" 2009, Vol. 18(2), pp. 89-137.

Aikman D., Ph. Barrett, S. Kapadia et al., Uncertainty in macroeconomic policy-making: art or science?, "Philosophical Transactions of the Royal Society" 2011, Vol. 369, pp. 4798-4817.

Barro R.J., Keynesian Economics vs. Regular Economics, “The Wall Street Journal”, $23^{\text {rd }}$ August 2011.

Barsky R., L. Kilian, Do We Really Know that Oil Caused the Great Stagflation? A Monetary Alternative, "NBER Macroeconomics Annual" 2001, No. 16.

Cathcart Th., The Trolley Problem, or Would You Throw the Fat Guy Off the Bridge? A Philosophical Conundrum, Workman Publishing, New York 2013.

Chugh S., Modern Macroeconomics, MIT Press, Cambridge, Massachusetts 2015.

${ }_{33}^{33}$ J. Keynes, op. cit., p. 50. 
Foot Ph., The Problem of Abortion and the Doctrine of the Double Effect, "Oxford Review" 1967, No. 5.

Greene J. et al., Pushing moral buttons: The interaction between personal force and intention in moral judgment, "Cognition" 2009, Vol. 111(3), pp. 364-371.

Han J., A. Saptawijaya, L. Pereira, Moral reasoning under uncertainty, "International Conference on Logic for Programming Artificial Intelligence and Reasoning”, Springer, Berlin 2012.

Keynes J., A Treatise on Probability, Dover Publications, Mineola 2013.

Klein L., IS-LM Model: Its Role in Macroeconomics [in:] IS-LM and Modern Macroeconomics, eds. W. Young, B. Zilberfarb, Springer, Tel Aviv 2012.

Knight F., Risk, Uncertainty and Profit, Dover Publications, New York 2012.

Krugman P., Fighting Off Depression, “The New York Times", $5^{\text {th }}$ January 2009, http://www.nytimes.com/2009/01/05/opinion/05krugman.html?_r=0 (retrieved: $26^{\text {th }}$ September 2009).

Lanteri A., Ch. Chelini, S. Rizzello, An Experimental Investigation of Emotions and Reasoning in the Trolley Problem, "Journal of Business Ethics" 2008, Vol. 83, pp. 789-804.

Lucas R., The other-worldly philosophers, “The Economist", $16^{\text {th }}$ July 2009, http://www.economist. com/node/14030288 (retrieved: $26^{\text {th }}$ September 2009).

Mäki U., Modelling failure [in:] H. Leitgeb, I. Niiniluoto et al., Logic, Methodology and Philosophy of Science - Proceedings of the $15^{\text {th }}$ International Congress, College Publications, Helsinki 2016.

Malkiel B., E. Fama, Efficient Capital Markets: A Review of Theory and Empirical Work, "The Journal of Finance" 1970 , Vol. 25(2), pp. 383-417.

Mankiw G., Principles of Microeconomics, Cengage Learning, New York 2008.

Maziarz M., The Reinhart-Rogoff controversy as an instance of the 'emerging contrary result' phenomenon, "Journal of Economic Methodology" 2017, Vol. 24(3), pp. 213-225.

Perkins J.O.N., The Reform of Macroeconomic Policy. From stagflation to Low or Zero Inflation, Palgrave MacMillan, Melbourne 2016.

Posner R., The Economics of Justice, Harvard University Press, Harvard 1983.

Shiller R., The Subprime Solution: How Today's Global Financial Crisis Happened, and what to Do about it, Princeton University Press, Princeton 2012.

Stiglitz J.E., Rethinking Macroeconomics: What Failed, and how to Repair It?, "Journal of the European Economic Association” 2011, Vol. 9(4), pp. 591-645.

Thomson J., The Trolley Problem, “The Yale Law Journal” 1985, Vol. 94(6), pp. 1395-1415. 